\title{
Predictive Direct Power Control of Doubly Fed Induction Generators to Reduce the Power Ripple During the Grid Synchronization
}

\author{
Ghazaleh Sarfi ${ }^{*}$, Mohsen Kalantar \\ Electrical Department, Iran University of Science and Technology, Tehran, Iran \\ Email address: \\ gh_sarfi@alumni.iust.ac.ir(G. Sarfi), kalantar@iust.ac.ir (M. Kalantar) \\ ${ }^{*}$ Corresponding author
}

\section{To cite this article:}

Ghazaleh Sarfi, Mohsen Kalantar. Predictive Direct Power Control of Doubly Fed Induction Generators to Reduce the Power Ripple During the Grid Synchronization. American Journal of Electrical Power and Energy Systems. Vol. 9, No. 6, 2020, pp. 97-103.

doi: $10.11648 /$ j.epes.20200906.11

Received: November 24, 2020; Accepted: December 7, 2020; Published: December 16, 2020

\begin{abstract}
This paper presents a new method of predicting power based on predictive direct power control. This method reduces power ripple in a doubly fed induction generator, which makes it possible to have a smoother synchronization with the grid in low constant frequency switching. To achieve fast and smooth grid synchronization without any over current, the difference between the measure, frequency, and the phase of the stator voltage and the grid voltage should be minimized. This condition can be achieved by minimizing the error between active and reactive virtual power and their references. By predicting the virtual active and reactive power behavior and choosing different active voltage vectors and using each of them at different times among each period time, the best switching of the rotor side converter in doubly fed induction generator to have a smoother condition can be chosen. In this paper, a $15 \mathrm{kw}$ generator is simulated by the classic method which is direct power control, and this new method, predictive direct power control, and it will be shown how much the new method reduces the power ripple to have a smoother synchronization that doesn't cause mechanical or electrical pressure for none of the grid and the doubly fed induction generator.
\end{abstract}

Keywords: Synchronization, Doubly Fed Induction Generator, Active and Reactive Virtual Power, Predictive Direct Power Control

\section{Introduction}

In recent years, using renewable energies inside distribution power networks such as smart-grids [1] and microgrids [2] has been developing. Among these renewable energies, wind energy is one of the fastest-growing [1]. Doubly fed induction generator (DFIG) is one of the best configurations in wind turbines. The DFIG has several advantages such as maximum power gain in $25 \%-30 \%$ of the generator rating and decoupled active and reactive power control [2]. This condition is prepared by a 2 -side converter which is located between the rotor of DFIG and the grid.

Grid synchronization of DFIG should be inspected to obtain a smooth and fast grid connection without any over current [3]. Several controlling methods are proposed to achieve this goal. The most famous one is vector control
(VC) with the d-axis oriented along with the rotor flux which is the conventional method for controlling the DFIG. In this method, the direct current of the rotor is proportional to the rotor flux while the quadrature current of the rotor is proportional to the electromagnetic torque. By controlling the two components of the current independently, a decoupled control with linear controllers such as PIs is obtained [4] \& [5]. This method needs a large amount of computing compared with direct control, which can be direct power control (DPC) or direct torque control (DTC). In this respect, this paper presents a new method of predictive direct power which can reduce the active/reactive power ripple especially for a low switching frequency that is forced to use in highpower wind turbines. In the direct control method, hysteresis comparators are used instead of PI regulators which are used in vector control, and this is another advantage for direct 
power control compared with vector control [6]. In direct power control, for each sampling time, one active voltage vector must be chosen and this is a limited choice. Therefore, active/reactive powers have a large amount of ripple in this method. To solve this problem we could predict the future behavior of active/reactive power and choose more than one active voltage vector for each sampling time that could reduce power ripple. Predictive direct power control (PDPC) can be applied by differentiating active and reactive power equations [7].

In this respect, this paper is organized as follows: models of DFIG in both stationary and rotary 2-phase frames are presented in Section 2. The grid synchronization condition and the algorithm and the differences between DPC and PDPC methods in the grid synchronization condition are described in section 3. Section 4 presents MATLAB simulation results and compares the two methods with respect to different aspects. Section 5 summarizes the paper with concluding remarks.

\section{Doubly Fed Induction Generator Modeling}

\subsection{Model of DFIG in Stationary 2-phase Frame}

In this frame, due to zero value for the rotating speed, the equations of machine's parameters are written as below:

Voltage equations:

$$
\begin{gathered}
\vec{v}_{s}^{s}=R_{s} \vec{i}_{s}^{s}+\frac{d \vec{\psi}_{s}^{s}}{d t} \\
\vec{v}_{r}^{s}=R_{r} \vec{i}_{r}^{s}+\frac{d \vec{\psi}_{r}^{s}}{d t}-j \omega_{m} \vec{\psi}_{r}^{s}
\end{gathered}
$$

Flux equations:

$$
\begin{gathered}
\vec{\psi}_{s}^{s}=L_{s} \vec{i}_{s}^{s}+L_{m} \vec{i}_{r}^{s} \\
\vec{\psi}_{r}^{s}=L_{m} \vec{i}_{s}^{s}+L_{r} \vec{i}_{r}^{s}
\end{gathered}
$$

where $\vec{v}_{s}^{s}, \vec{i}_{s}^{s}, \vec{\psi}_{s}^{s}, \vec{v}_{r}^{s}, \vec{i}_{r}^{s}, \vec{\psi}_{r}^{s}$ are the stator voltage, stator current, stator flux, rotor voltage, rotor current, and rotor flux vectors, respectively. In addition, $R_{s}$ and $R_{r}$ are stator and rotor resistances, $L_{s}$ and $L_{r}$ are stator and rotor inductances, $L_{m}$ is mutual inductance which is transferred to stator side and $\omega_{m}$ is the electrical rotor speed [8].

\subsection{Model of DFIG in Rotary 2-phase Frame}

In this frame that the rotating speed is equal to the rotor speed, the equations of machine's parameters are [9]:

Voltage equations:

$$
\begin{gathered}
\vec{v}_{s}^{r}=R_{s} \vec{i}_{s}^{r}+\frac{d \vec{\psi}_{s}^{r}}{d t}+\omega_{m} \vec{\psi}_{s}^{r} \\
\vec{v}_{r}^{r}=R_{r} \vec{i}_{r}^{r}+\frac{d \vec{\psi}_{r}^{r}}{d t}
\end{gathered}
$$

Power equations:

$$
\begin{gathered}
p_{s}=\frac{3}{2} \frac{L_{m}}{\sigma L_{s} L_{r}} \omega_{s}\left|\vec{\psi}_{s}\right|\left|\vec{\psi}_{r}\right| \sin \delta \\
Q_{s}=\frac{3}{2} \frac{\omega_{s}}{\sigma L_{s}}\left|\vec{\psi}_{s}\right|\left[\frac{L_{r}}{L_{m}}\left|\vec{\psi}_{s}\right|-\left|\vec{\psi}_{r}\right| \cos \delta\right]
\end{gathered}
$$

where $\omega_{s}$ is the synchronous speed, $\delta$ is the angle between rotor and stator fluxes and $\sigma$ is leakage factor which is equal to:

$$
\sigma=1-\frac{L_{m}{ }^{2}}{L_{r} L_{s}}
$$

\section{Grid Synchronization}

To have a smooth grid connection without any over current, the difference between measure, frequency, and phase of the stator voltage and the grid voltage must be zero. To obtain this condition, the controlling system of DFIG should prepare the grid synchronization which is introduced.

\subsection{Grid Synchronization Condition}

In synchronization mode, the breaker between the grid and DFIG is already open which means the stator current is zero. Therefore, in (3) and (4), the first term is zero which leads to the below equation.

$$
\theta_{\psi_{r}}=\theta_{\psi s}
$$

which means rotor and stator fluxes are in the same phase [5, $10]$.

\subsection{Principle of Virtual Active/Reactive Power}

In grid synchronization condition, a virtual principal is introduced for active/reactive power due to the same phase for rotor and stator fluxes. Therefore, in (7) and (8), $\delta$ is always zero, which means that it is not appropriate to apply the controlling system. Therefore, a new principle named virtual grid flux is introduced to solve the problem [11].

As it obvious, for having a safe and smooth grid connection without any over current, the stator voltage and the grid voltage must be exactly the same. Therefore, with help of (1) and a zero stator current, we have:

$$
\psi_{s}=\psi_{g}
$$

Now from (3), (4) and (11), the relevance between the rotor flux and virtual grid flux to prepare the grid 
synchronization is as below:

$$
\psi_{r}=\frac{L_{r}}{L_{m}} \psi_{g}
$$

By substituting the virtual grid flux in (7) and (8), the virtual active/reactive power equations will be:

$$
\begin{gathered}
p_{v}=\frac{3}{2} \frac{L_{m}}{\sigma L_{s} L_{r}} \omega_{g}\left|\vec{\psi}_{g}\right|\left|\vec{\psi}_{r}\right| \sin \delta \\
Q_{v}=\frac{3}{2} \frac{\omega_{g}}{\sigma L_{s}}\left|\vec{\psi}_{g}\right|\left[\frac{L_{r}}{L_{m}}\left|\vec{\psi}_{g}\right|-\left|\vec{\psi}_{r}\right| \cos \delta\right]
\end{gathered}
$$

\section{DPC Method}

In this method, the error between active/reactive virtual power and their references should be minimized.

In synchronization condition, equation (12) shows that $\delta$ is equal to zero. By substituting zero as $\delta$ in (13) and (14), active/reactive virtual power references during the grid synchronization will be obtained as below $[12,13]$.

$$
\begin{gathered}
p_{v}=\frac{3}{2} \frac{L_{m}}{\sigma L_{s} L_{r}} \omega_{g}\left|\vec{\psi}_{g}\right|\left|\frac{L_{r}}{L_{m}} \vec{\psi}_{g}\right| \sin 0=0 \\
Q_{v}=\frac{3}{2} \frac{\omega_{g}}{\sigma L_{s}}\left|\vec{\psi}_{g}\right|\left[\frac{L_{r}}{L_{m}}\left|\vec{\psi}_{g}\right|-\left|\frac{L_{r}}{L_{m}} \vec{\psi}_{g}\right| \cos 0\right]=0
\end{gathered}
$$

Equations (15) and (16) show that the grid synchronization will be obtained if active/reactive virtual power references are zero. To provide this, the measure of rotor flux and $\delta$ should be changed, because other terms such as the measure of virtual grid flux which is shown in (17) are constant.

$$
\left|\vec{\psi}_{g}\right|=\frac{\left|\vec{v}_{g}\right|}{\omega_{g}}
$$

Figure 1 shows how this method works. In addition, Figure 2 shows how final rotor flux can provide wanted, which is changed by voltage vector applied to rotor winding. This voltage vector is chosen by block No. 4 in Figure 1 which identifies the error between active/reactive virtual power and their references, after passing the hysteresis bands. This block works in accordance with Table 1 [14].

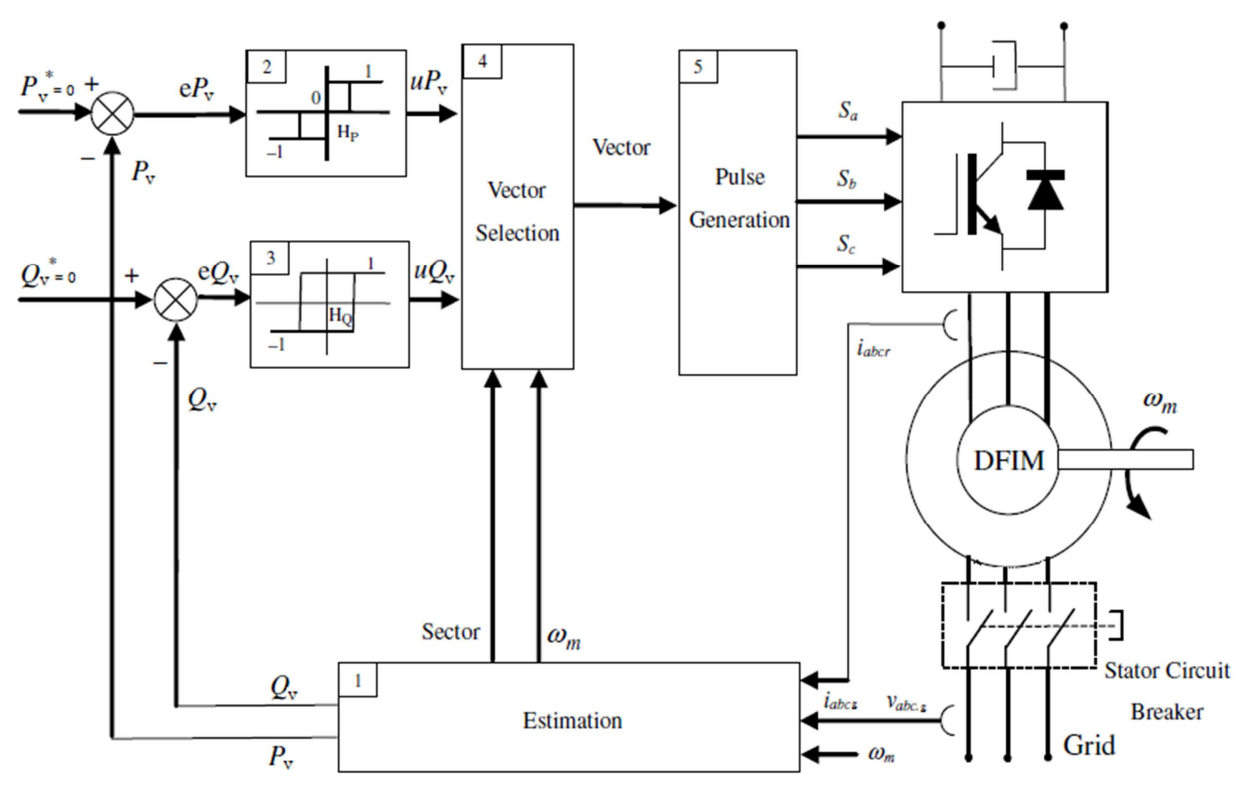

Figure 1. Block diagram of DPC method.

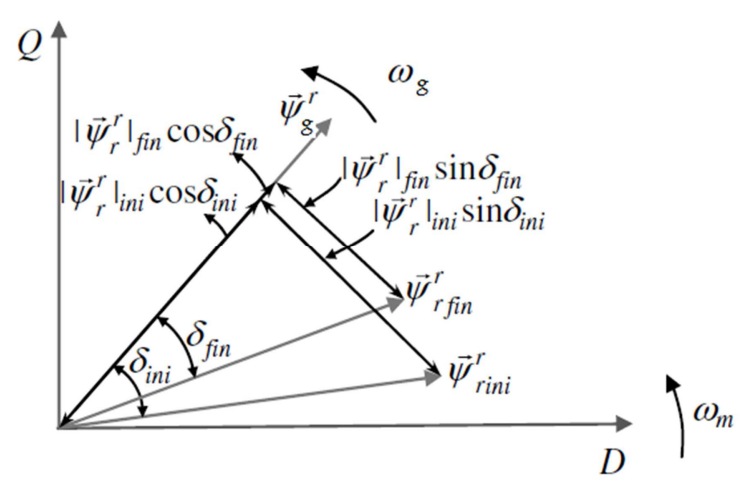

Figure 2. Changes of rotor flux by applying voltage vector.
Table 1. Voltage vector switching table ( $k=$ sector).

\begin{tabular}{lllll}
\hline $\boldsymbol{u} \boldsymbol{P}_{\boldsymbol{v}}$ & & $\mathbf{1}$ & $\mathbf{0}$ & $\mathbf{- 1}$ \\
\hline$u Q_{v}$ & 1 & $v_{(k-1)}$ & $v_{0}, v_{7}$ & $v_{(k+1)}$ \\
& -1 & $v_{(k-2)}$ & $v_{0}, v_{7}$ & $v_{(k+2)}$ \\
\hline
\end{tabular}

In this table, $\mathrm{k}$ represents the position of initial rotor flux, which is obtained by block 1 of Figure 1.

\section{PDPC Method}

PDPC method is based on predicting the future behavior of 
the active/reactive virtual power. According to Table 1 and DPC method, only one voltage vector in each sampling time is chosen and applied to the relevant switching of rotor side converter, which is just six active voltage vectors and two zero vectors [15]. Therefore, by predicting the future behavior in each sampling time, three voltage vectors, consist of two active vectors and one zero vector can be applied to reduce the active/reactive power ripple.

Figure 3 illustrates the future behavior of active/reactive power. The third sloop is produced by applying zero voltage vector and the other two sloops are produced by choosing active voltage vectors to minimize the active/reactive power ripple. Each of these vectors should apply during specific times to provide wanted.

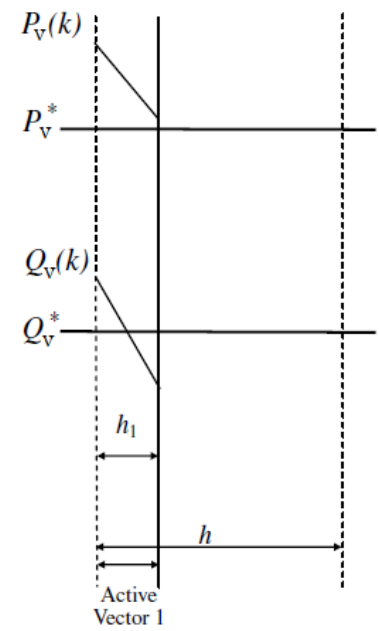

(a)

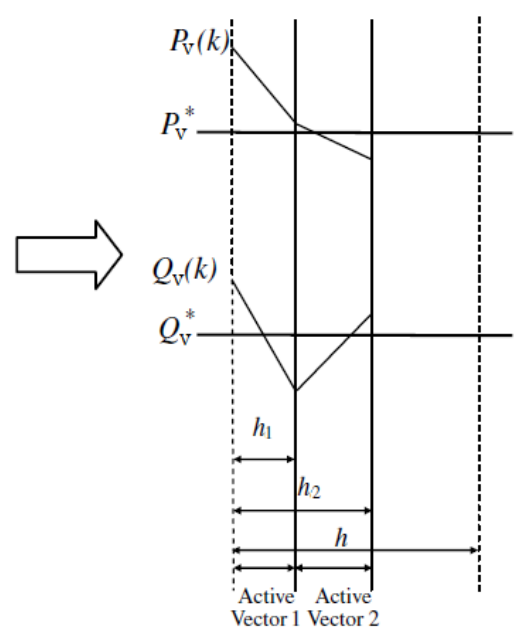

(b)

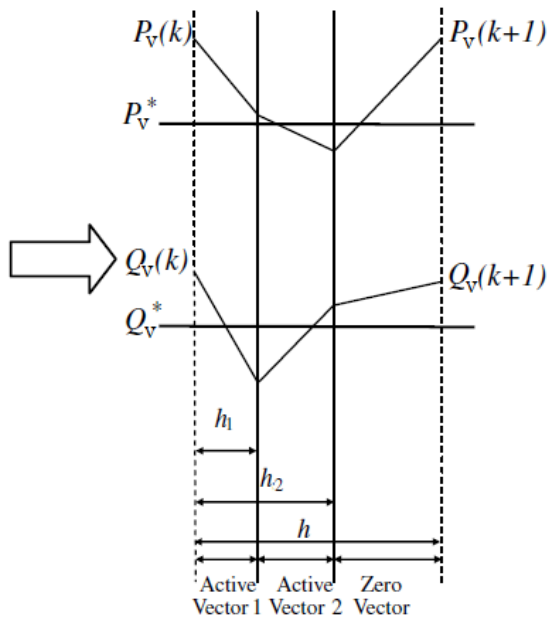

(c)

Figure 3. Active /reactive virtual power evolutions during one sampling time h by applying (a) first (b) second (c) zero voltage vectors.

Therefore, the following equations should be minimized [3]:

$$
\begin{gathered}
Q_{V_{\text {ripple }}}{ }^{2}=\frac{1}{h_{2}} \int_{0}^{h_{1}}\left(s_{Q_{1}} t+Q_{v}(k)-Q_{v}^{*}\right)^{2} d t+\frac{1}{h_{2}} \int_{h_{1}}^{h_{2}}\left(s_{Q_{2}} t-s_{Q_{2}} h_{1}+s_{Q_{1}} h_{1}+Q_{v}(k)-Q_{v}^{*}\right)^{2} d t \\
P_{V_{\text {ripple }}}{ }^{2}=\frac{1}{h} \int_{0}^{h_{2}}\left(s_{12} t+P_{v}(k)-P_{v}^{*}\right)^{2} d t+\frac{1}{h} \int_{h_{2}}^{h}\left(s_{P_{3}} t-s_{P_{3}} h_{2}+s_{12} h_{2}+P_{v}(k)-P_{v}^{*}\right)^{2} d t
\end{gathered}
$$

where $Q_{v}(k)$ and $P_{v}(k)$ are active/reactive virtual powers which are obtained by (13) and (14). In addition, the references of $Q_{v}(k)$ and $P_{v}(k)$ are $Q_{v}^{*}$ and $P_{v}^{*}$ which according to (15) and (16) are equal to zero during the synchronization condition. $s_{Q_{1}}, s_{Q_{2}}, s_{P_{3}}$ are active/reactive virtual power sloops and $s_{12}$ is:

$$
s_{12}=\frac{s_{p_{1}} h_{1}+s_{p_{2}}\left(h_{2}-h_{1}\right)}{h_{2}}
$$

At last, according to Figure $3, h_{1},\left(h_{2}-h_{1}\right),\left(h-h_{2}\right)$ are suitable times for applying each voltage vector to minimize (18) and (19). Therefore we have [2]:

$$
\begin{gathered}
h_{1}=\frac{2 s_{Q_{2}}\left(\mathrm{P}_{v}^{*}-P_{v}(k)\right)-s_{Q_{2}} s_{P_{3}} h}{2 s_{Q_{2}} s_{P_{1}}-4 s_{Q_{1}} s_{P_{2}}+2 s_{Q_{1}} s_{P_{3}}-s_{Q_{2}} s_{P_{3}}}+\frac{\left(2 s_{P_{3}}-4 s_{P_{2}}\right)\left(Q_{v}^{*}-Q_{v}(k)\right)}{2 s_{Q_{2}} s_{P_{1}}-4 s_{Q_{1}} s_{P_{2}}+2 s_{Q_{1}} s_{P_{3}}-s_{Q_{2}} s_{P_{3}}} \\
h_{2}=\frac{\left(2 s_{Q_{2}}-4 s_{Q_{1}}\right)\left(\mathrm{P}_{v}^{*}-P_{v}(k)\right)+\left(2 s_{Q_{1}}-s_{Q_{2}}\right) s_{P_{3}} h}{2 s_{Q_{2}} s_{P_{1}}-4 s_{Q_{1}} s_{P_{2}}+2 s_{Q_{1}} s_{P_{3}}-s_{Q_{2}} s_{P_{3}}}+\frac{\left(4 s_{p_{1}}-4 s_{p_{2}}\right)\left(Q_{v}^{*}-Q_{v}(k)\right)}{2 s_{Q_{2}} s_{P_{1}}-4 s_{Q_{1}} s_{P_{2}}+2 s_{Q_{1}} s_{P_{3}}-s_{Q_{2}} s_{P_{3}}}
\end{gathered}
$$

Equations (21) and (22) are useful, when $s_{P_{1}}$ and $s_{P_{2}}$ are in a same direction. Otherwise, $h_{1}$ and $h_{2}$ will be obtained by: 


$$
\begin{gathered}
h_{1}=\frac{2 s_{Q_{2}}\left(\mathrm{P}_{v}^{*}-P_{v}(k)\right)-s_{Q_{2}} s_{P_{3}} h}{2 s_{Q_{2}} s_{P_{1}}-4 s_{Q_{1}} s_{P_{2}}+2 s_{Q_{1}} s_{P_{3}}-s_{Q_{2}} s_{P_{3}}}+\frac{\left(2 s_{P_{3}}-4 s_{P_{2}}\right)\left(Q_{v}^{*}-Q_{v}(k)\right)}{2 s_{Q_{2}} s_{P_{1}}-4 s_{Q_{1}} s_{P_{2}}+2 s_{Q_{1}} s_{P_{3}}-s_{Q_{2}} s_{P_{3}}}+\frac{\left(s_{P_{2}}-2 s_{P_{1}}\right)\left(Q_{v}^{*}-Q_{v}(k)\right)+s_{Q_{1}}\left(P_{v}^{*}-P_{v}(k)\right)}{2 s_{Q_{2}} s_{P_{1}}-4 s_{Q_{1}} s_{P_{2}}+2 s_{Q_{1}} s_{P_{3}}-s_{Q_{2}} s_{P_{3}}} \\
h_{2}=\frac{\left(2 s_{Q_{2}}-4 s_{Q_{1}}\right)\left(P_{v}^{*}-P_{v}(k)\right)+\left(2 s_{Q_{1}}-s_{Q_{2}}\right) s_{P_{3}} h}{2 s_{Q_{2}} s_{P_{1}}-4 s_{Q_{1}} s_{P_{2}}+2 s_{Q_{1}} s_{P_{3}}-s_{Q_{2}} s_{P_{3}}}+\frac{\left(4 s_{p_{1}}-4 s_{p_{2}}+2 s_{3}\right)\left(Q_{v}^{*}-Q_{v}(k)\right)}{2 s_{Q_{2}} s_{P_{1}}-4 s_{Q_{1}} s_{P_{2}}+2 s_{Q_{1}} s_{P_{3}}-s_{Q_{2}} s_{P_{3}}}
\end{gathered}
$$

To achieve Figure 3, the first voltage vector is chosen by Table 1, regardless of zero voltage vector and the second voltage vector is chosen by Table 2 . The third sloop which is provided by zero voltage vector could be positive or negative. This matter depends on either subsynchronism or hypersynchronism conditions of DFIG which means it rotates either faster or slower than synchronism speed [16].

Table 2. The second voltage vector switching table ( $k=$ sector).

\begin{tabular}{lccc}
\hline $\boldsymbol{u} \boldsymbol{P}_{\boldsymbol{v}}$ & $\mathbf{1}$ & $\mathbf{- 1}$ \\
\hline \multirow{3}{*}{$u Q_{v}$} & 1 & $v_{(k+2)}$ & $v_{(k+1)}$ \\
& -1 & $v_{(k-2)}$ & $v_{(k-1)}$ \\
\hline
\end{tabular}

At the end, we should consider that the relation between the sampling time $h, h_{l}$ and $h_{2}$ is as below:

$$
h\rangle h_{2}, h_{2}>h_{1}, h_{1}>0
$$

If (25) does not happen, it means that active/reactive virtual powers are far from their references. In this condition, we use DPC method and only one voltage vector will be chosen.

\section{Simulation Results}

In this paper, a $15 \mathrm{kWDFIG}$ based on parameters in Table 3 is considered as the case study. In the next step, both DPC and PDPC methods are applied to this case study and compared to each other. The main purpose is to see how much each method could reduce the active/reactive virtual power before grid connection and also active/reactive power after grid connection [1]. The sampling frequency for both DPC and PDPC is 50 $\mathrm{kHz}$ and the hysteresis band for PDPC is zero.

Table 3. DFIG parameters.

\begin{tabular}{ll}
\hline Rated generator power & $P_{\text {gen }}=15 \mathrm{KW}$ \\
DC-bus voltage & $V_{d c}=500 \mathrm{~V}$ \\
\hline
\end{tabular}

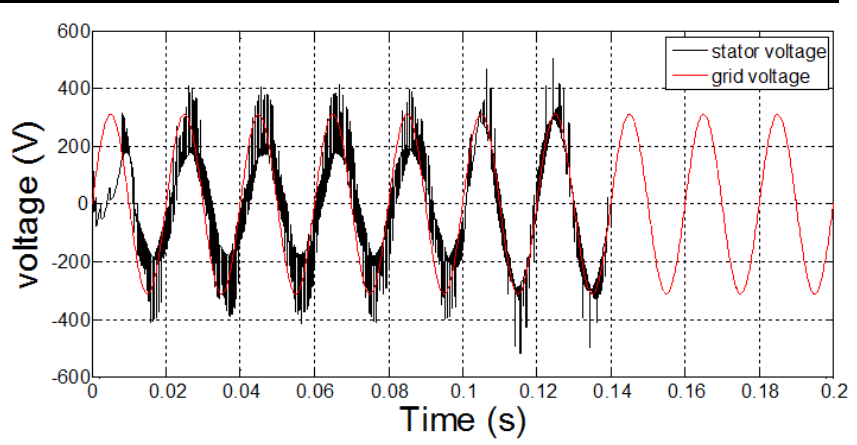

(a)

\begin{tabular}{ll}
\hline Rated generator voltage & $V_{L-L}=380 \mathrm{~V}$ \\
Rated generator frequency & $f_{S}=50 \mathrm{~Hz}$ \\
Number of generator pairs & $P=2$ \\
Stator resistance & $R_{s}=0.168 \Omega$ \\
Rotor resistance & $R_{r}^{\prime}=0.199 \Omega$ \\
Stator inductance & $L_{S s}=0.05 \mathrm{H}$ \\
Rotor inductance & $L_{r r}^{\prime}=0.05 \mathrm{H}$ \\
Mutual inductance & $L_{m}=0.045 \mathrm{H}$ \\
\hline
\end{tabular}

In this simulation, before the grid connection, the active/reactive virtual power references for providing the grid synchronization should be zero but after the grid-connected, references that are not virtual anymore should be $P_{\text {gen }}=15$ $\mathrm{kW}$ and $Q_{\text {gen }}=18.347 \mathrm{kVAR}$ to have the rated power. In addition, before grid synchronization, it could be these amounts to arrive grid synchronization condition more easily, see Figure 4.

Therefore, the grid synchronization starts at $\mathrm{t}=0.1 \mathrm{sec}$ and the DFIG connects to the grid at $\mathrm{t}=0.14 \mathrm{sec}$, but applying the new power references arises at $\mathrm{t}=0.17 \mathrm{sec}$. Noted that, Figure 5 indicates the behavior of active/reactive power before the grid synchronization, during that and after the grid connection by applying DPC method as an example.

Figure 6 shows active/reactive virtual power during the grid synchronization by applying DPC method and Figure 7 shows active/reactive virtual power during the grid synchronization by applying PDPC method. Therefore by comparing Figure 4, Figure 6 and Figure 7, it is obvious that how much PDPC method can reduce the power ripple and prepare more suitable condition. And at last Figure 8 indicates the stator currents during the grid synchronizations and after grid-connected, most when active/reactive power references are still zero and we have no-load conditions. From Figure 8 is also obvious that by PDPC method, current ripple reduces, so a smoother grid connection is obtained.

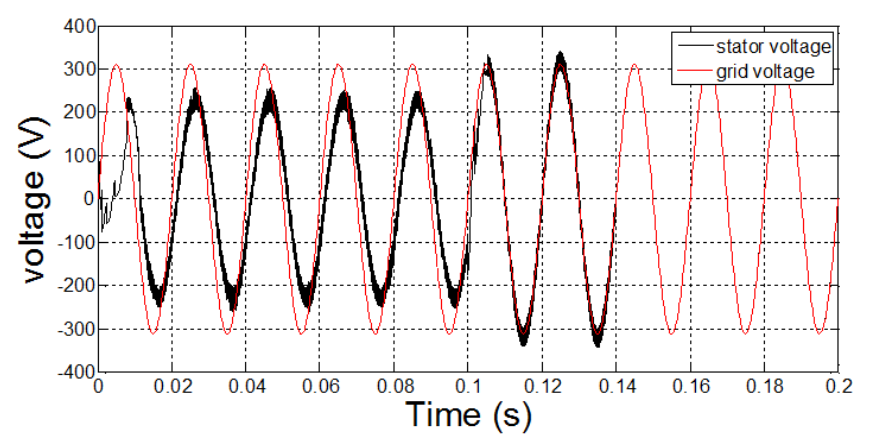

(b)

Figure 4. The stator voltage and the grid voltage: (a) by DPC method (b) by PDPC method. 


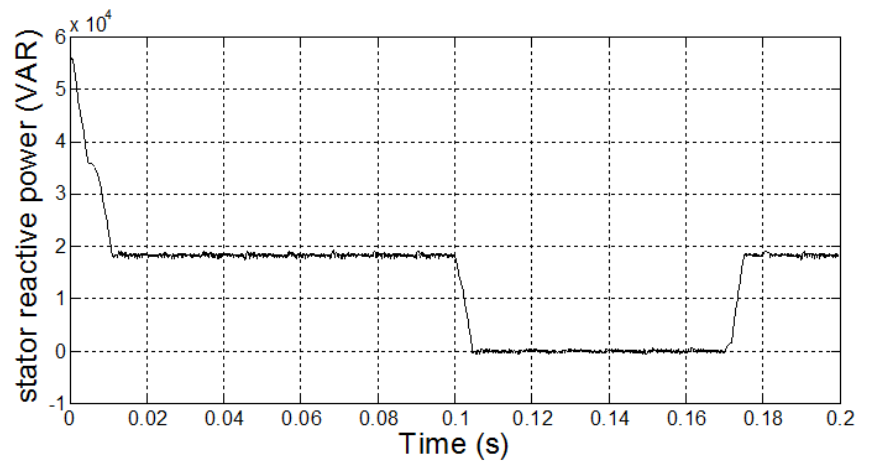

(a)

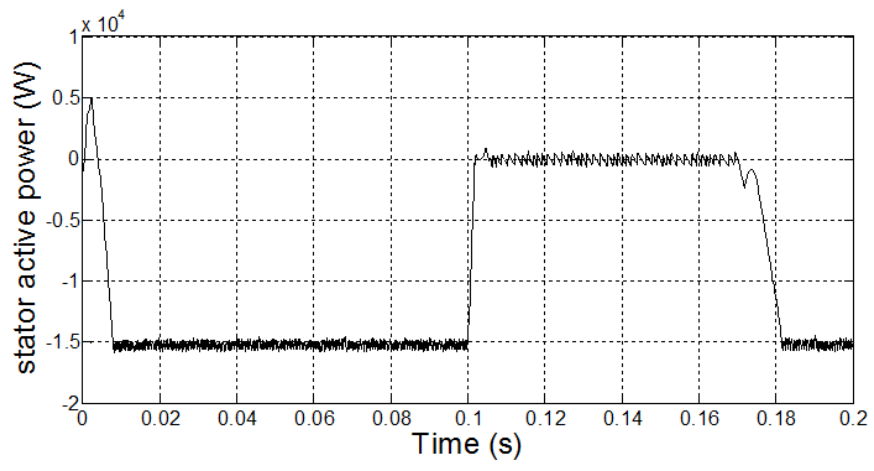

(b)

Figure 5. The behavior of active/reactive power before the grid synchronization, during the grid synchronization and after the grid connected, by applying DPC method: (a) reactive power, (b) active power.

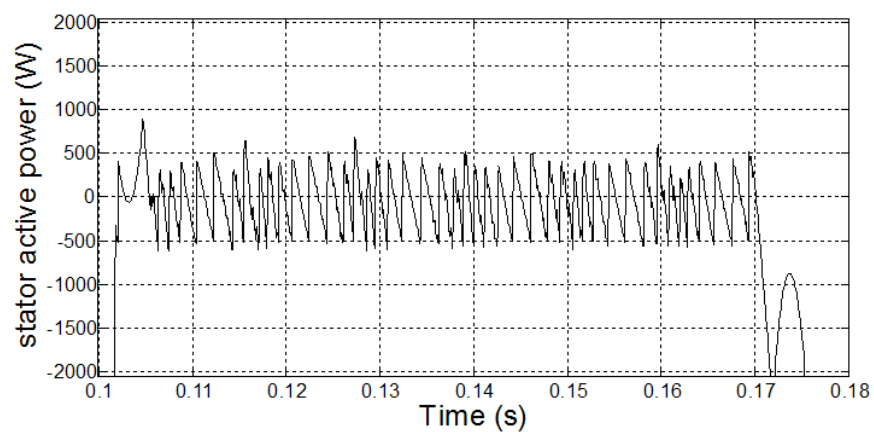

(a)

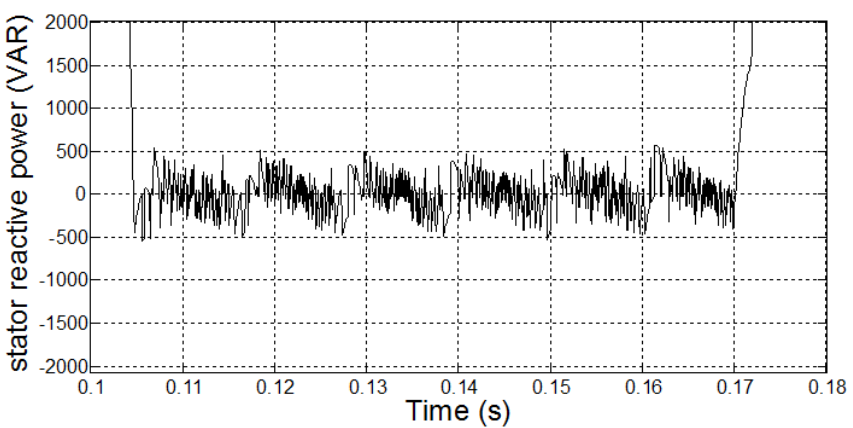

(b)

Figure 6. (a) Active virtual power (b) Reactive virtual power, during the grid synchronization by applying DPC method.

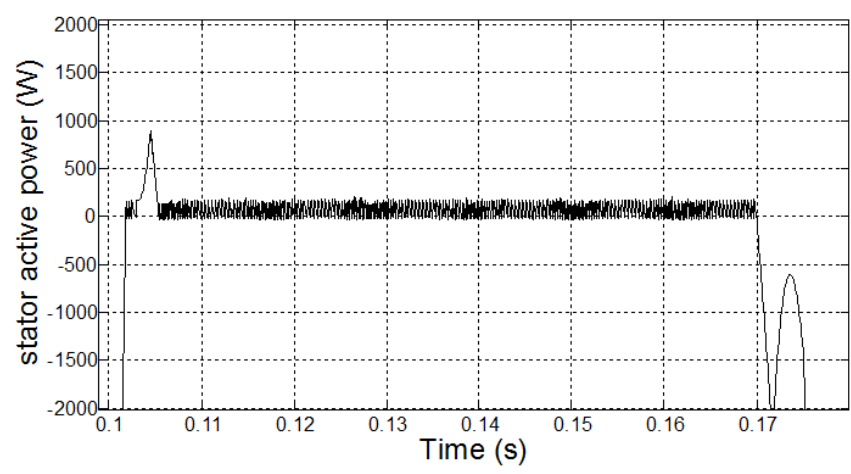

(a)

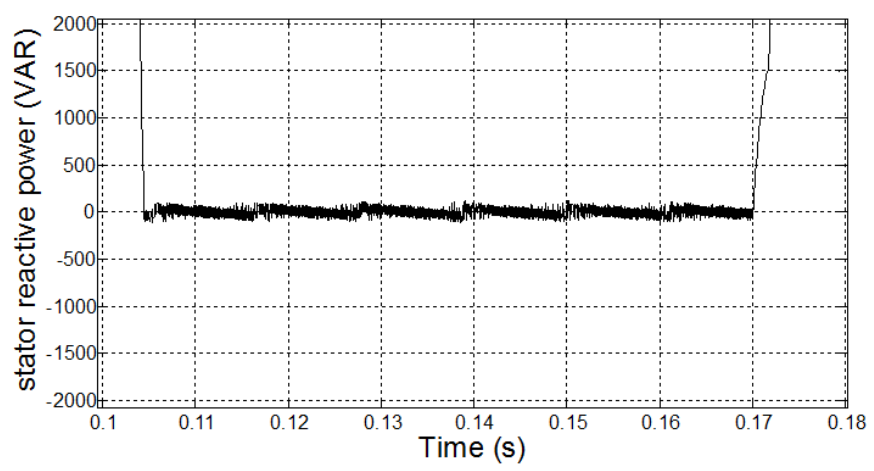

(b)

Figure 7. (a) active virtual power (b) reactive virtual power, during the grid synchronization by applying PDPC method.

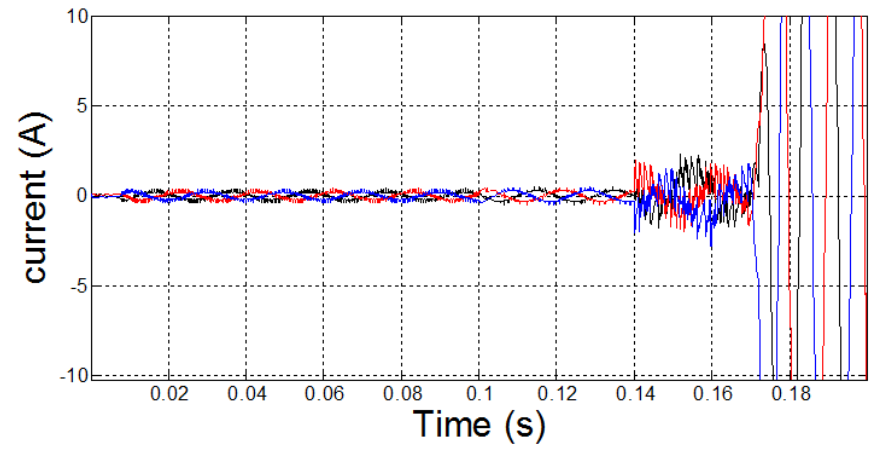

(a)

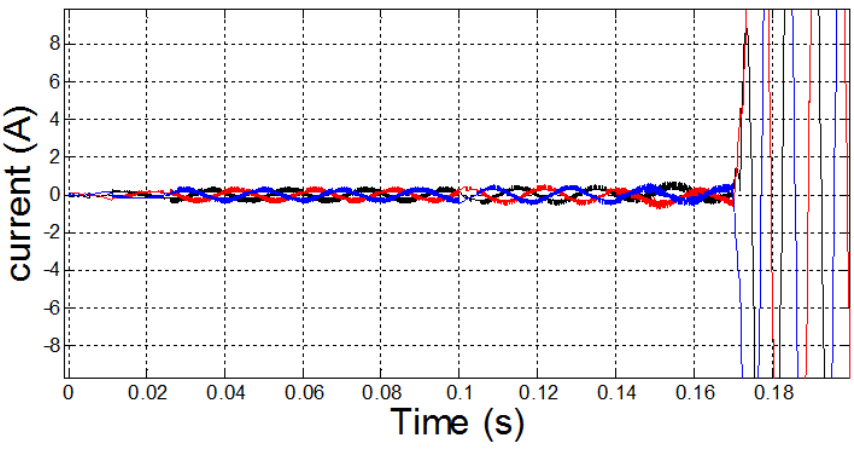

(b)

Figure 8. The stator current: (a) by DPC method (b) by PDPC method. 


\section{Conclusion}

This paper presents a new method for predicting the future behavior of active/reactive virtual power (which represents active/reactive power of stator if it was connected to the grid) based on DPC method, named predictive direct power control (PDPC). By this new method, the power ripple reduces, which provides the better condition at a low constant switching frequency to have a smoother grid connection. Therefore, this method is useful when we are forced to use low constant switching frequency for instant in a high power unit. In PDPC method the grid voltage and the stator voltage become more like each other, so a safer grid connection that doesn't cause mechanical or electrical pressure for both the grid and the DFIG is obtained.

\section{References}

[1] R. Jalilzadeh Hamidi and H. Livani, "Distributed cooperative control system for smart microgrids," Electric Power Systems Research, Vol. 130, pp. 241-250, 2016.

[2] V. Sarfi, I. Niazazari, and H. Livani, "Multiobjective fireworks optimization framework for economic emission dispatch in microgrids." North American Power Symposium (NAPS), 2016, pp. 1-6, Nov. 2016.

[3] Sam Mahmodicherati, Malik Elbuluk, Yilmaz Sozer, "Grid synchronization for a virtual direct power-controlled DFIG wind power System" Energy Conversion congress and exposition (ECCE), IEEE, 2015.

[4] Jiefeng $\mathrm{Hu}$, Jianguo Zhu, Yongchang Zhang, "Predictive Direct Virtual Torque and Power Control of Doubly Fed Induction Generators for Fast and Smooth Grid Synchronization and Flexible Power Regulation", IEEE Transactions on power electronics, Vol 28, No 7, 2013.

[5] Şevki Demirbaş, Sertaç Bayhan, "Grid Synchronization of Doubly Fed Induction Generator in Wind Power Systems" IEEE Transactions on Energy and Electrical Drives (POWERENG), International Conference, 2011

[6] Gonzalo Abad, Jesu's Lo'pez, Miguel A. Rodri'guez, Luis Marroyo, Grzegorz Iwanski, "Doubly fed induction machine; modeling and control for wind energy generation" Director of IEEE Book and Information Services (BIS).
[7] Yongchang Zhang, Jiefeng Hu, Jianguo Zhu, "Three-VectorsBased Predictive Direct Power Control of Doubly Fed Induction Generator for Wind Energy Applications", IEEE Transactions on power electronics, Vol 29, No 7, 2014.

[8] Yongchang Zhang, Zhengxi Li, Wei Xu, Jiefeng Hu, Jianguo Zhu, "Grid Synchronization of DFIG Using Model Predictive Direct Power Control" IEEE Transactions on Electrical Machines and Systems (ICEMS) International Conference, 2011.

[9] Jiefeng $\mathrm{Hu}$, Jianguo Zhu, Yongchang Zhang, Glenn Platt, David G. Dorrell, and Qishuang Ma, "Predictive Direct Control of Doubly Fed Induction Generator for Grid Synchronization in Wind Power Generation" Energy Conversion Congress and Exposition (ECCE) IEEE, 2011.

[10] Si Zhe Chen, Norbert C. Cheung, Yun Zhang, Miao Zhang, Xiong Min Tang, "Improved Grid Synchronization Control of Doubly Fed Induction Generator Under Unbalanced Grid Voltage" IEEE Transaction on energy conversion vol. 26, No. 3, 2011.

[11] S. Muller, M. Deicke, R. De Doncker, "Doubly fed induction generator systems for wind turbines" IEEE industry application magazine, May|June 2002.

[12] Jiabing Hu; Heng Nian; Hailiang Xu; Yikang He, "Dynamic modeling and improved control of DFIG under distorted grid voltage conditions"; Energy Conversion, IEEE Transaction, Vol 26, 2010.

[13] Francoise Mei, and Bikash Pal, "Modal Analysis of GridConnected DoublyFed Induction Generators" IEEE Transaction on energy conversion, vol. 22, No. 3, 2007.

[14] Ahmed G. Abo-Khalil, "Synchronization of DFIG output voltage to utility grid in wind power system" Elsevier, Vol 44, 2012.

[15] M. Khalilzadeh, S. Vaez-Zadeh and A. Jabbarnejad, "A Model-Free Approach for Predictive Direct Power Control of Grid-Connected Converters," IECON 2019 - 45th Annual Conference of the IEEE Industrial Electronics Society, Lisbon, Portugal, 2019, pp. 6141-6146.

[16] E. A. Al-Ammar, H. Ur Rahman Habib, A. Waqar, S. Wang, M. M. Rahman and A. Ahmed, "Predictive Direct Power Control of Voltage Source Converters in Microgrids during Reconfiguration, " 2020 Advances in Science and Engineering Technology International Conferences (ASET), Dubai, United Arab Emirates, 2020, pp. 1-6. 